\title{
DESIGN E ILUSTRAÇÃO: A FRAGILIDADE DA FORMAÇÃO DE ILUSTRADORES NO BRASIL
}

Mônica Lopes Nogueira, MSc.

Universidade Estácio de Sá

ilustredesign@gmail.com

Rita Maria de Souza Couto, Dr ${ }^{a}$

PUC-Rio

ricouto@puc-rio.br

Flávia Nízia da Fonseca Ribeiro, Drạ

PUC-Rio

flavianizia@gmail.com

Resumo: $O$ presente artigo tem como objetivo trazer à discussão a demanda dos alunos que querem ser ilustradores e que, sem nenhuma formação acadêmica para a área, acabam ingressando em sua maioria, no design. Esse dado é apresentado através do resultado de questionário realizado em vários grupos de discussão on-line em âmbito nacional e que estão relacionados ao tema. Através dessa pesquisa, foi verificado que poucos são aqueles que se sentem satisfeitos com a graduação escolhida. Além disso, atualmente, é possível perceber que alguns cursos de design oferecem graduações tecnológicas que anunciam em sua denominação a Ilustração, porém se analisadas as grades curriculares, basicamente não há muitas disciplinas que aprofundam realmente a área. Ao longo do texto é apresentada também as fragilidades no cenário brasileiro para a formação de ilustradores, atividade que não faz parte ainda da lista de profissões do Ministério do Trabalho. Os dados aqui apresentados fazem parte de uma pesquisa em andamento de doutorado em design, que busca estabelecer quais assuntos são pertinentes à formação de um ilustrador.

Palavras-chave: Ilustração, llustrador, Formação acadêmica.

\begin{abstract}
The present paper aims to discuss the needs and aspirations of the students who want to be illustrators and that, without academic formation, start to study design. This result is shown through accomplished research at online discussion groups, at a national level. Throughout the research, it was verified that many students aren't satisfied with their choice of graduation. Besides that, currently, it's possible to realize that some design schools offer technological graduations that announce in their denomination the illustration. But, when these curriculum are analyzed, basically it's perceived that there are few disciplines that really deepen in the area. In this text is displayed also the weaknesses of the Brazilian
\end{abstract}


scenario to the illustrator's formation. This activity is not present on the official list of recognized professions of the Labor Ministry. The data shown here is part of a doctorate research still in progress, that seeks to stablish which aspects are important to an illustrator's formation.

Keywords: Illustration, Illustrator, Academic education

\section{INTRODUÇÃO}

Atualmente, para que uma pessoa escolha uma graduação que proporcione um ingresso mais qualificado no mercado de trabalho, é possível contar, dentro do cenário brasileiro de formação superior, com diversas opções de escolha.

Porém, para certas carreiras é necessário cursar uma graduação em uma área afim e, posteriormente, realizar vários outros cursos que complementem sua formação inicial capacitando o formando para trabalhar realmente no ramo desejado.

Uma das carreiras que no Brasil ainda carece de especialização é o do ilustrador. Após um extenso levantamento verificou-se que não existe, registro de uma graduação brasileira específica para a formação de ilustradores profissionais, nem tecnológica e nem em bacharelado. O que existe é a oferta de uma graduação que poderíamos chamar de híbrida, ao oferecer cursos que conjugam, por exemplo, animação e ilustração digital ou comunicação e ilustração digital. Porém, quando analisada a grade curricular, é possível perceber que quase não há disciplinas específicas sobre ilustração nesses cursos.

No portal do e-MEC ${ }^{1}$, dedicado a consultas on-line sobre Instituições de Ensino Superior (IES), em uma busca pelo termo "ilustração" na opção de nomes de cursos de graduação, foi possível encontrar apenas sete instituições cadastradas no Ministério da Educação (MEC) que oferecem graduação tecnológica em "Comunicação e Ilustração Digital", único termo, até o momento, utilizado pelo MEC para graduações que utilizam ilustração no nome, as quais estão listadas abaixo²:

- Instituição A - (Goiânia/ GO);

- Instituição B - (São José/SC);

- Instituição C - (Vitória/ES);

- Instituição D - (Salvador/BA);

- Instituição E - (Foz do Iguaçu/PR);

- Instituição F - (Campo Grande/MS);

- Instituição G - (Teresina/PI).

Uma busca no Google, utilizando o mesmo termo - "Comunicação e Ilustração Digital" - além das IES mencionadas acima foram encontradas também:

- Instituição H - (Brasília/DF);

- Instituição I - (Maceió/AL);

- Instituição J - (Fortaleza/CE).

Entretanto, algo interessante foi percebido em relação a essas dez IES. Elas

\footnotetext{
${ }^{1}$ http://emec.mec.gov.br/

${ }^{2}$ Os nomes das IES foram preservados.
} 
possuem a mesma grade curricular, além também do mesmo layout de site, diferenciando uma das outras apenas pelo nome da instituição, que, aliás, também em termos de elementos visuais de marca são bem semelhantes. Aparentemente parecem ser gerenciadas por uma única rede de ensino.

Analisando brevemente essa grade curricular única, é possível perceber que se trata mais de um curso tecnológico em design generalista do que realmente ensino de ilustração e da formação de um ilustrador.

Mudando as palavras-chave de "Comunicação e Ilustração Digital" por "graduação" e "ilustração", encontra-se ainda através do Google, a Instituição H no Rio de Janeiro/RJ com uma graduação tecnológica "llustração e Animação Digital", disponível dentre as opções de formação em design. Igualmente, ao analisar sua grade curricular, apesar desta estar mais voltada para ilustração, ainda é dedicado muito espaço para assuntos que envolvem animação e design.

Com pouca possibilidade de formação específica na área de ilustração, a escolha mais comum, de acordo com a pesquisa a ser apresentada mais a frente, é o curso de graduação em design.

É válido ressaltar que no Brasil, para ser ilustrador não é necessário ter uma graduação, porém ter uma formação acadêmica pode auxiliar esse futuro profissional com relação às diversas possibilidades de representação em ilustração, bem como ajudá-lo a inserir-se no restrito mercado de trabalho, possibilitando que ele planeje estratégias de posicionamento e visibilidade.

Normalmente os cursos de design e de áreas afins não tratam a ilustração como objeto principal de ensino, mas, de certa forma, por meio de suas disciplinas conseguem auxiliar no processo de criação de ilustrações como, por exemplo, ensinar noções de teoria das cores, conhecimento utilizado pelo aluno em suas produções.

Porém, por experiência, percebe-se que muitos alunos que querem ser ilustradores ingressam no curso de design relativamente desinformados. Estes, sentem forte desejo de atuarem na área e começam a graduação acreditando que irão desenhar a todo o momento.

Assim, é de extrema importância para os cursos design observarem essa questão. Quando um aluno entra em um tipo de curso e sente que o mesmo não é exatamente aquilo que ele esperava, isso pode fazer com que ele sinta vontade de abandoná-lo, aumentando o número de evasão.

A seguir será apresentado o resultado da pesquisa realizada com pessoas que já são ou que desejam ser ilustradoras profissionais por intermédio de 154 grupos de discussão on-line $i$ em âmbito nacional, relacionados ao tema.

\section{O PERFIL DOS ILUSTRADORES E DOS FUTUROS ILUSTRADORES}

Foi realizado um questionário on-line aplicado no período de 7 de maio a 08 de junho de 2016, com o intuito de entender um pouco mais o perfil de ilustradores profissionais e futuros ilustradores brasileiros, incluindo pessoas que já trabalham na área ou que queiram trabalhar. As perguntas foram realizadas por meio de uma plataforma virtual ${ }^{3}$ e divulgadas em vários grupos de discussão referentes ao tema no Facebook, além também da divulgação através do "Ilustragrupo", um fórum de discussão por e-mail.

\footnotetext{
${ }^{3}$ https://www.typeform.com/
} 
Ao total foram obtidas 489 respostas de pessoas de diversos lugares, os quais foram gerados alguns dados bem interessantes, a serem apresentados a seguir.

Em relação à faixa etária, grande parte desses ilustradores ou futuros profissionais que aqui chamarei de "aspirantes a ilustrador" tem idade abaixo de 28 anos (aproximadamente 60,3\% do total). Ou seja, pessoas jovens que possivelmente estão buscando uma forma de se posicionarem no mercado de trabalho.

\section{Gráfico 1 - Faixa etária dos participantes da pesquisa}

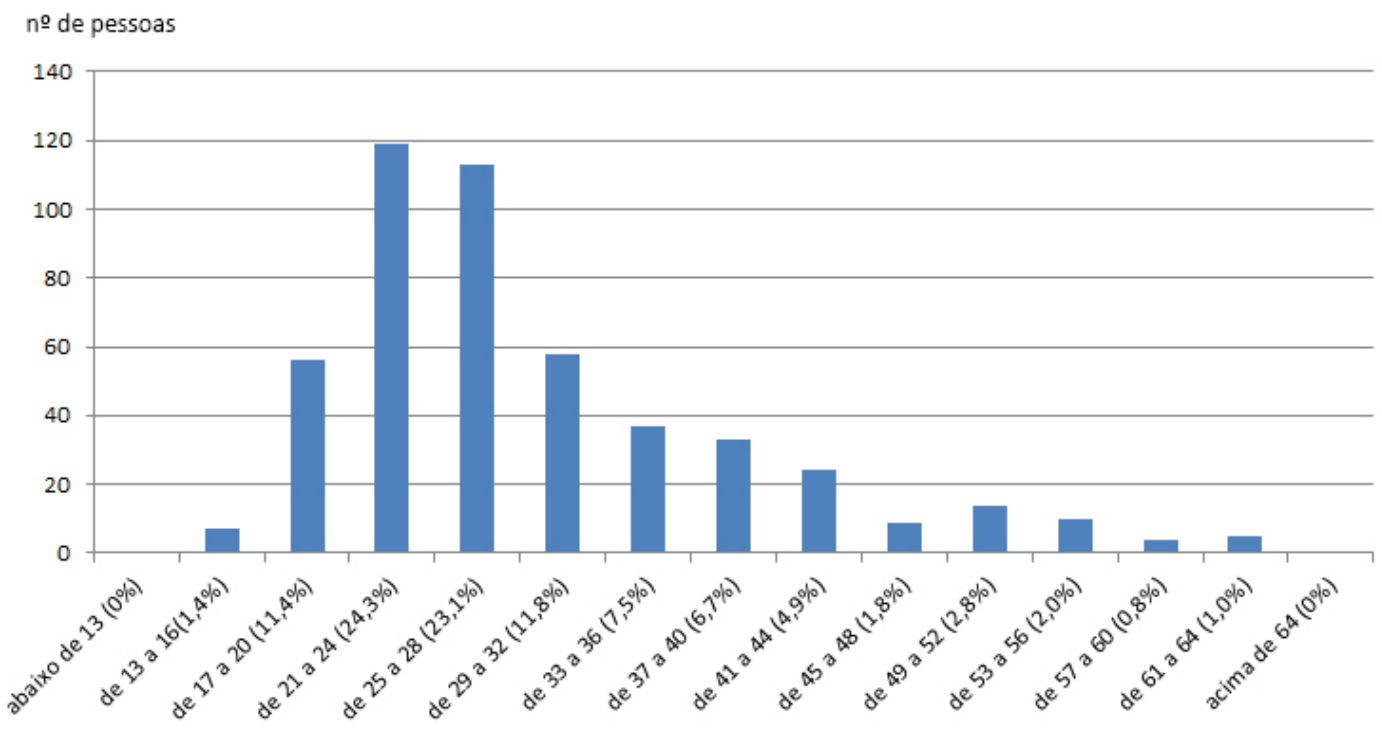

Uma parte dos participantes, 207 pessoas (aproximadamente 42,3\%), se considera um ilustrador profissional, vendendo os seus trabalhos, mesmo sem algum tipo de regularidade. Porém, quando questionados se vivem somente de ilustração, apenas 59 pessoas (aproximadamente 12,0\%) disseram que sim. Dentre esses que ganham dinheiro somente através de ilustração, 49,1\% tem idade entre 25 a 36 anos.

Por meio desse questionário foi percebido que mesmo não havendo uma graduação específica para a área, este público continuou seus estudos, visto que 420 pessoas (aproximadamente 85,8\%) possuem algum tipo de formação acadêmica, mesmo que incompleta. Outro dado interessante foi que 196 pessoas (aproximadamente 40,3\%) ainda estão cursando a graduação, correspondendo a quase metade do público. 
Gráfico 2 - Escolaridade dos participantes da pesquisa

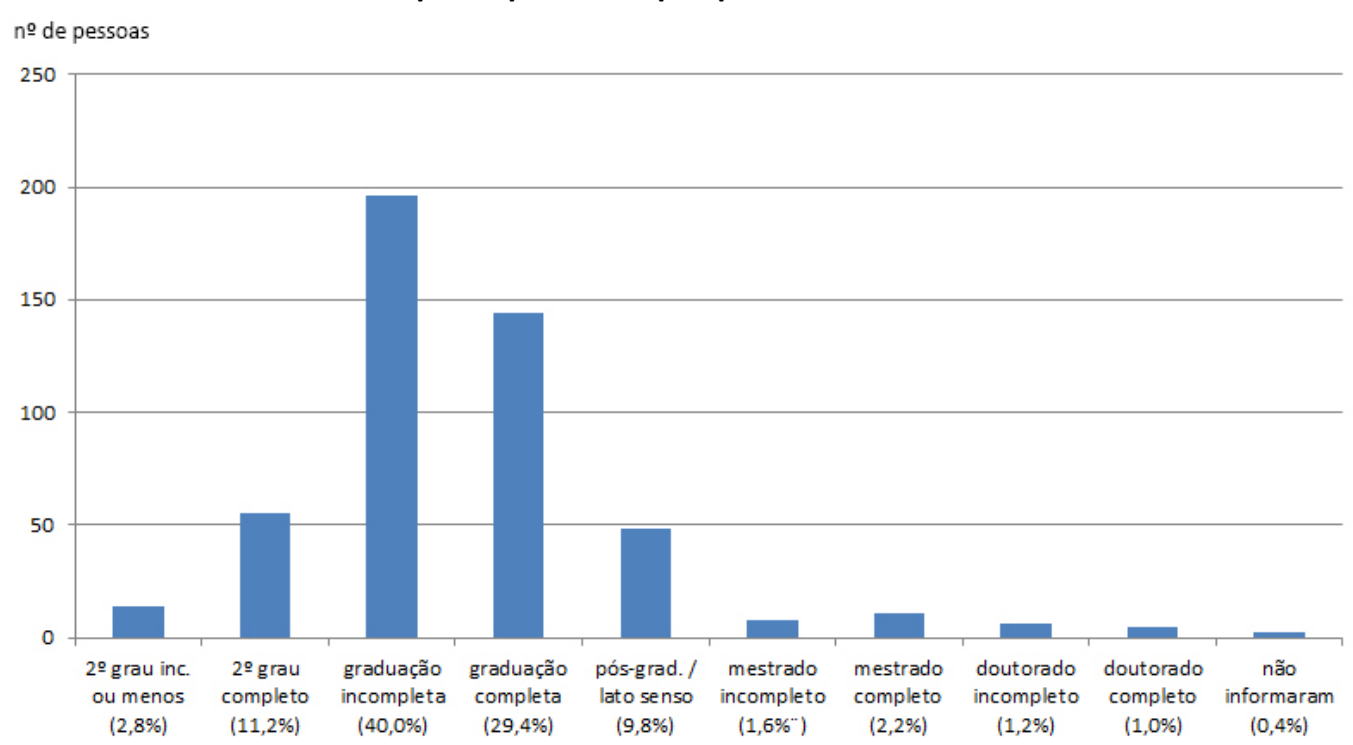

Em relação à escolaridade foi realizada uma pergunta particular para os que tinham e outra para os que não tinham formação acadêmica.

Assim, quando questionados aqueles que não tinham ainda uma formação, se eles achavam que uma graduação em outra área iria ajudá-los em sua profissão como ilustrador, 42 pessoas (aproximadamente 60,8\% desse grupo) acreditavam que sim, enquanto 17 pessoas (aproximadamente $24,6 \%$ desse grupo) acreditavam que não. Dez pessoas (aproximadamente $14,4 \%$ desse grupo) não responderam ou não souberam opinar. Ou seja, por mais que ainda não tenham feito a escolha de qual faculdade fazer, a maioria desse grupo ainda enxerga a universidade como algo a agregar em sua formação enquanto ilustrador.

Gráfico 3 - Opinião dos participantes com formação de até 2 -grau completo em relação a se uma graduação ajudaria em sua formação como ilustrador

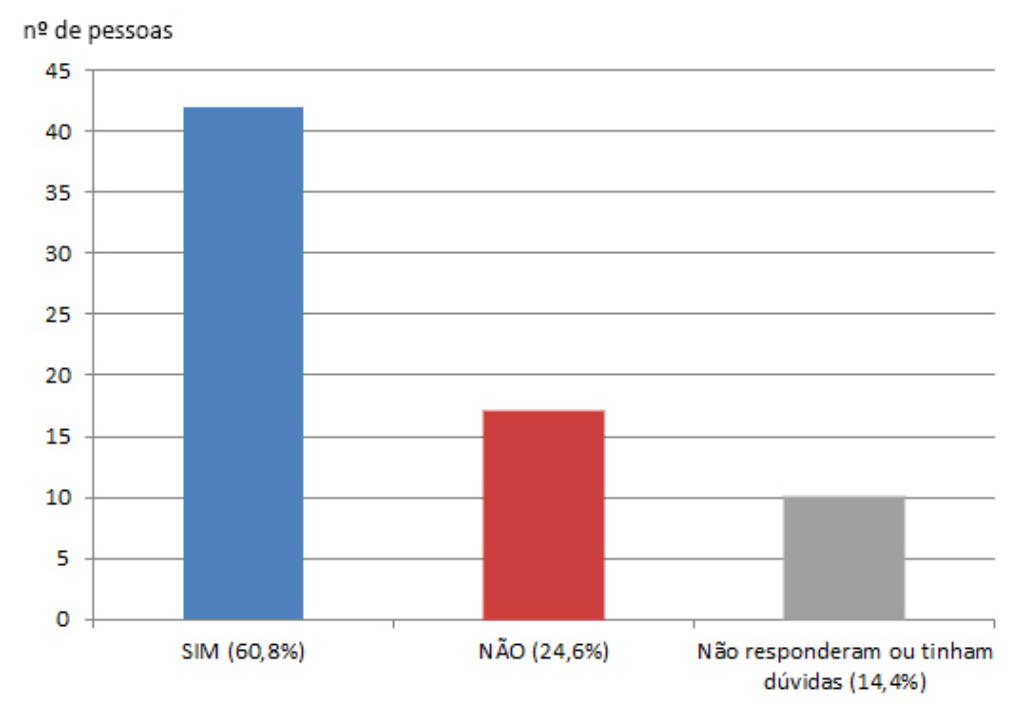

Dentre aqueles que possuíam uma graduação ou que ainda estavam cursando, um fato agravante foi observado, do total de pessoas que responderam ao questionário, 215 pessoas (aproximadamente $42,1 \%$ do total de participantes) 
escolherem o curso de graduação pensando em serem ilustradoras. Porém, 131 pessoas (aproximadamente $60,9 \%$ desse grupo) relataram que a graduação escolhida não atendeu as suas expectativas, enquanto apenas 84 pessoas (aproximadamente $39,1 \%$ desse grupo) se sentiram satisfeitas com a graduação escolhida em relação ao estudo da ilustração.

Dos que responderam que ilustração não foi o motivo inicial para a escolha da graduação, mas que surgindo o interesse posterior não se sentiram satisfeitas com o curso escolhido temos 139 pessoas (aproximadamente 84,2\% dos que tiveram interesse posterior a escolha da graduação), em contrapartida a somente 26 pessoas (aproximadamente $15,8 \%$ desse último grupo) que, mesmo não tendo a ilustração como foco inicial para a escolha da graduação, se sentiram satisfeitas com o que aprenderam, pois conseguiram perceber relação do curso escolhido com a ilustração. Ainda em relação a esse quesito, 43 pessoas (aproximadamente $8,7 \%$ do total de participantes) não quiseram ou não souberam opinar.

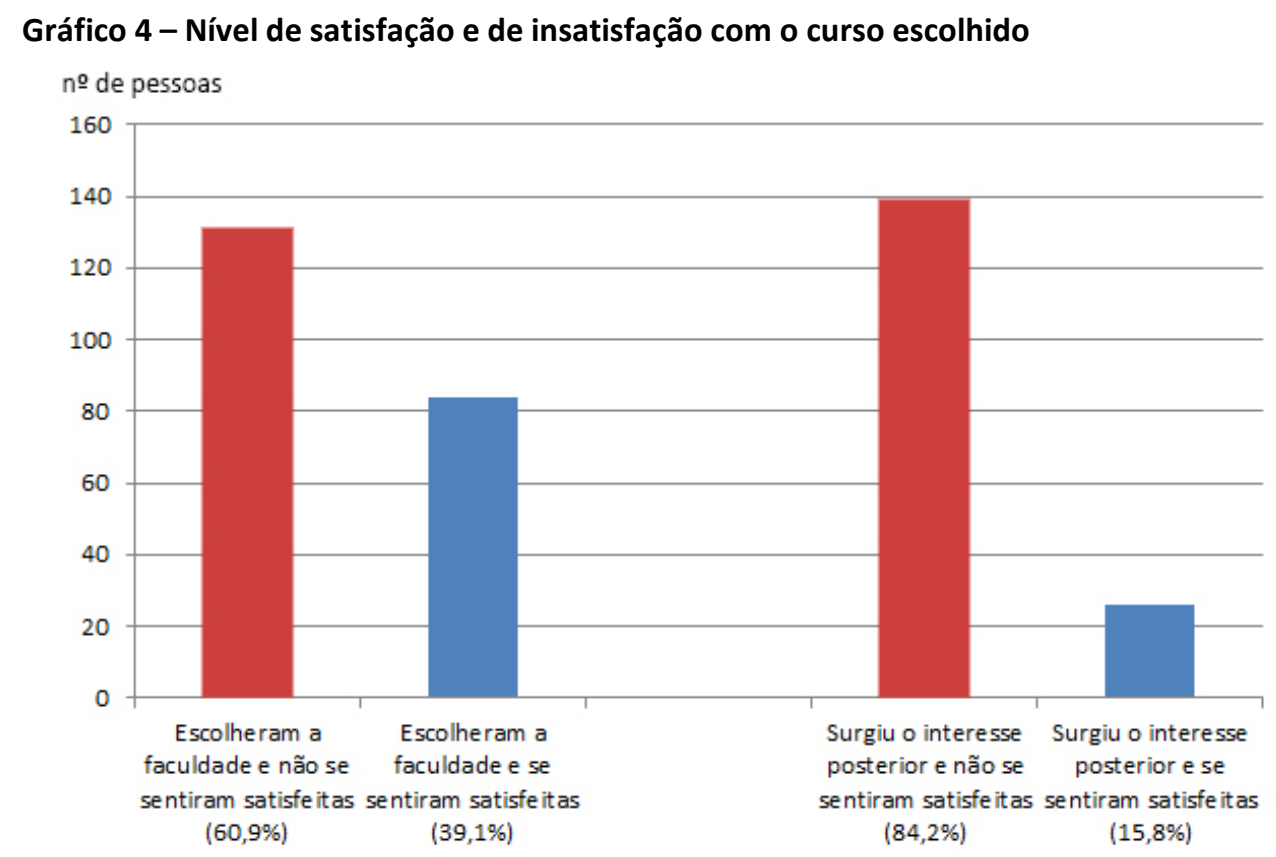

Relacionando os dois gráficos acima, tais dados demonstram que por mais que as pessoas que tenham até $2^{\circ}$ grau completo acreditem que fazer uma graduação ajudaria em sua formação, estes ao começarem a estudar provavelmente se sentirão decepcionados com a escolha que fizeram.

Dos 489 participantes que responderam ao questionário, 202 pessoas (aproximadamente 41,3\%) fazem ou fizeram Design, 73 pessoas (aproximadamente 14,9\%) graduação relacionada a Artes (Belas Artes, Artes Visuais, Arte Plástica, Educação Artística, Licenciatura em Artes etc.), 32 pessoas (aproximadamente 6,5\%) Publicidade e Propaganda, 18 pessoas (aproximadamente 3,6\%) Ciências Biológicas, 12 pessoas (aproximadamente 2,4\%) áreas relacionadas à Informática (Ciência da Computação, Sistemas de Informação, Computação Gráfica etc.), oito pessoas (aproximadamente 1,6\%) Ciências Sociais, cinco pessoas (aproximadamente 1,0\%) letras, 41 pessoas (aproximadamente 8,3\%) outros tipos de curso, enquanto 115 pessoas (aproximadamente 23,5\%) não informaram o tipo de curso realizado. 


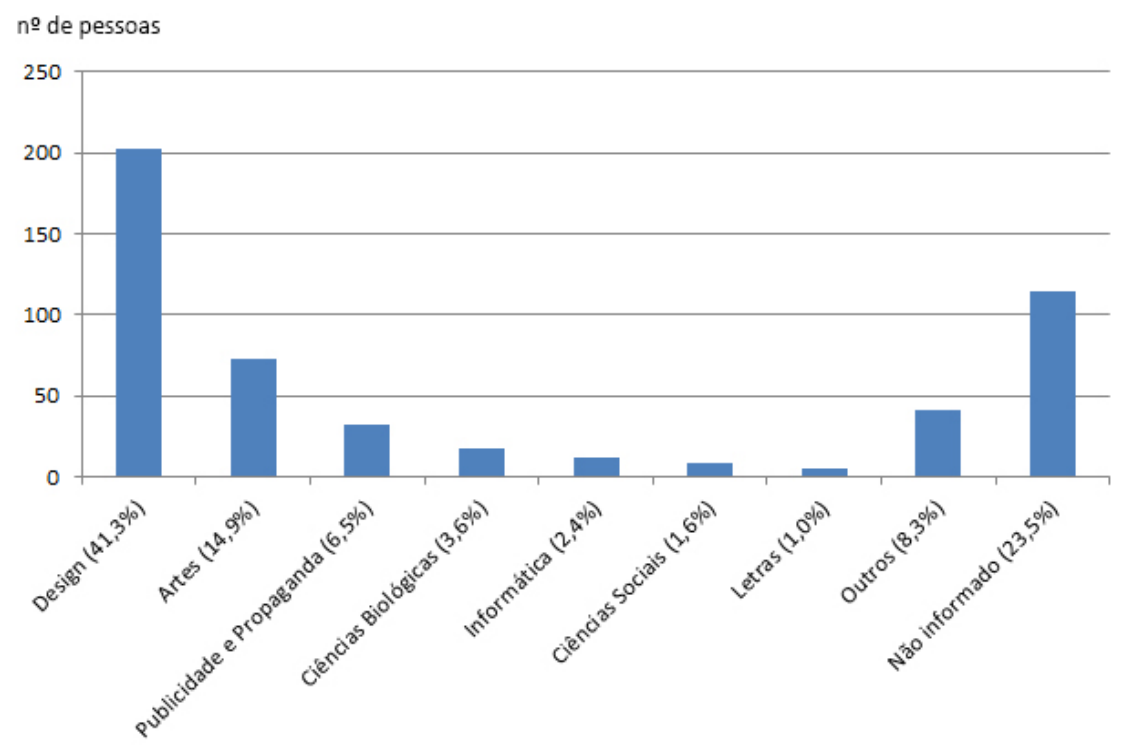

Ou seja, pela pesquisa foi possível observar que há uma grande preferência por Design e áreas relacionadas à Arte, seguido de Publicidade e Propaganda. Foi interessante também notar que estudantes de Ciências Biológicas procuram a área por conta da ilustração científica, assunto pouco explorado dentro da própria área de ilustração.

Continuando, quando observada as questões pelas quais as faculdades não corresponderam às expectativas desses estudantes encontramos, na maior parte dos casos, reclamações que giram em torno da graduação não abordar ou abordar de forma superficial a área da ilustração. Muitos entraram na graduação achando que estudariam de alguma forma o tema e quando perceberam, quase nada foi aprendido (em relação a área).

Quando suas graduações abordaram o assunto "ilustração", os entrevistados relataram que houve pouco aprofundamento e em pouquíssimas disciplinas. Em alguns casos a disciplina não ensinava os fundamentos da ilustração, mas somente o ensino de softwares, bem como o uso de conteúdos que são facilmente encontrados em tutoriais na internet.

Na opinião de alguns alunos falta prática em ilustração, falta um ensino mais voltado para torná-los empreendedores ao invés de simples empregados, falta abordar assuntos mais relacionados à profissão de ilustrador (carreira, produção de contratos, abrir empresa, como se comportar no mercado de trabalho etc.), falta incentivo da faculdade para explorar o tema, além do preconceito ainda existente em relação a ilustração (em suas opiniões encontram-se relatos que a ilustração é mal vista dentro de Belas Artes, pois não é pintura, bem como mal vista em Design, pois nessa área é vista como fazendo parte de Belas Artes).

É possível perceber também o descontentamento de alguns em relação ao próprio ensino obtido, pois as reclamações não foram só apenas relacionadas à falta de abordagem do tema, mas também a questões administrativas de suas faculdades, como ensino fraco, professores despreparados, conteúdo raso, falta de foco no ensino e falta de equipamentos específicos, como por exemplo, mesas digitalizadoras. 
Ou seja, para grande parte do público não há informação suficiente para quem quer ser ilustrador. Entretanto, não só houve reclamações, algumas pessoas (poucas) conseguiram apontar que apesar da faculdade não ser direcionada para ilustração, conseguiram fazer um paralelo entre o que aprendiam e a ilustração em si. Segundo esses participantes, na faculdade entraram em contato com questões mais teóricas e boas fontes bibliográficas, ampliando seus universos e complementando de alguma forma tangencial suas ilustrações.

A seguir são apresentados alguns comentários interessantes que foram escritos em perguntas abertas:

"Quando estudei na $[\ldots]^{4}$, tive algumas aulas de desenho, porém os professores eram pouco participativos. Um professor em particular (popular entre os alunos pela sua carisma) contentava-se em chamar modelos e apenas cronometrar o tempo das poses. Nunca o vi falar sobre gesto, espaço negativo, design, nada disso. Além disso, o que me fez deixar a instituição foi a quantidade baixa de matérias relacionadas, o que é compreensível, visto que meu curso era design, não ilustração. Acho que para dar certo, seria necessário um curso próprio de graduação e que desse ênfase nos fundamentos e preparasse os alunos para o mercado atual (jogos, filmes, animações, livros)" - Participante $A^{5}$, Design, RJ.

"Gostaria que houvesse uma especialização ou formação superior própria para esta profissão. Com conteúdos adequados como desenho, estilos, manipulação de ferramentas e materiais, desde tecnológicas a manuais, composições de cenários, cores e tudo que diz respeito a criação e execução de ilustrações. Gostaria de uma formação que o foco realmente fosse a ilustração e não ter que ficar procurando em vários lugares diferentes para obter o básico até mesmo para iniciar um aprendizado mínimo sobre o assunto." - Participante B, Design, RJ.

"Gostaria de saber, porque o design gráfico, sendo um curso onde seu nome se remete ao desenho, porque existem tão poucas matérias sobre o assunto?" Participante C, Design, RJ.

"Me pergunto porque ainda não existe faculdade ou tecnólogo de ilustração, explicando os fundamentos do desenho, composição, comunicação através da imagem e a parte narrativa." - Participante D, Design, SP.

"Gostaria que houvesse mais material sobre carreira. O início é sempre difícil e a ilustração abrange tantos caminhos que fica difícil começar com segurança." Participante E, Design, SP.

"Quais os conteúdos que devo estudar? Que curso fazer? Ser graduado é realmente importante? Como começar nesse ramo?" - Participante F, 2o grau incompleto ou menos, localidade não informada.

\footnotetext{
${ }^{4}$ Foi preservado o nome da instituição para não haver julgamento do curso, pois se trata apenas de uma experiência frustrada de um único aluno.

${ }^{5} \mathrm{O}$ nome das pessoas também foi preservado.
} 
Esses são apenas alguns dos comentários recebidos no questionário, mas que não se diferem da maioria. De uma maneira geral, os dados obtidos demonstram ser urgente a questão de se olhar para esse público para que simplesmente não desistam de ter uma formação acadêmica.

\section{A FORMAÇÃO DO ILUSTRADOR NO BRASIL}

Para ser ilustrador hoje no Brasil, como mencionado acima, não é necessário nenhum tipo de estudo, o que de certa maneira pode parecer vantajoso. Se não há necessidade de fazer nenhum cursinho ou uma graduação, quem queira trabalhar na área pode entrar no ramo e produzir suas artes a qualquer instante.

Essa facilidade pode até parecer boa em um primeiro momento, porém há alguns fatores complicantes os quais merecem reflexão: se qualquer pessoa pode reproduzir qualquer coisa a qualquer momento, haverá demasiadas pessoas no mercado, tornando-o saturado. Com muitas pessoas oferecendo seus serviços, haverá a necessidade de se destacar entre elas. Porém, sem nenhum tipo de formação voltada realmente para as questões que envolvem o tema ilustração, possivelmente haverá um grande oferecimento de trabalhos de baixa qualidade nesse mercado saturado.

Por sua vez, se não há formação, logo pouquíssimos irão se destacar (sejam aqueles que experimentam bastante, buscando realmente uma boa orientação e um bom resultado, sejam aqueles que já tinham facilidade para o desenho de forma intuitiva). Esse resultado nos faz ter a falsa impressão de que, se poucos conseguem chegar a um nível elevado, é possível realmente acreditar que ilustrar e/ou desenhar é um dom dado a apenas certas pessoas. Além disso, sem uma formação mais consolidada, possivelmente haverá pouca organização desses indivíduos enquanto grupo, consequentemente haverá pouca pressão para o reconhecimento da área e/ou da profissão, bem como haverá pouca valorização do trabalho.

Atualmente a profissão "ilustrador" ainda não faz parte da Classificação Brasileira de Ocupações ${ }^{6}$ disponibilizada no portal do Ministério do Trabalho e Emprego. É como se não existisse sequer essa profissão para o Governo Federal. De acordo com a ABRIPO (2006), o maior problema do mercado de ilustração está ligado ao fato de a profissão de ilustrador ser ignorada pelos órgãos governamentais, o que corrobora com uma das reflexões encontradas também no Guia do llustrador, escrito por Ricardo Antunes:

Em termos jurídicos ela simplesmente não existe, e, consequentemente não existem também escolas, faculdades ou cursos de formação profissional de ilustrador. Apenas cursos de artes onde se ensinam as técnicas de desenho e pintura, sem nunca se falar da postura profissional. (ANTUNES, p. 3, 2007)

Como forma de se protegerem diante desse cenário desolador, há no mercado brasileiro alguns profissionais que tentam se unir a fim de se reconhecerem enquanto grupo, buscando também refletirem em conjunto sobre a área. No caso dos ilustradores, encontramos:

\footnotetext{
${ }^{6} \mathrm{http}: / /$ www.mtecbo.gov.br/cbosite/pages/regulamentacao.jsf\#i
} 
- Sociedade dos llustradores do Brasil (SIB) fundada em 2001;

- Associação Brasileira dos llustradores Profissionais (ABRIPO) fundada em 2006;

- Associação dos Cartunistas do Brasil (ACB) fundada em 1988;

- Associação de Escritores e Ilustradores de Literatura Infantil e Juvenil (AEI-LIJ) fundada em 1998;

- União Nacional dos ilustradores Científicos (UNIC) fundada em 2006;

- Grafistas Associados do Rio Grande do Sul (GRAFAR) fundado em 1988;

- Associação Brasileira de desenhista de Mangá e ilustrações (ABRADEMI) fundada em 1984;

- Ilustragrupo (um fórum via e-mail de llustradores do Brasil) criado em 2007;

- etc.

Todos relativamente novos, porém alguns parecem estar abandonados, pois os assuntos mais recentes em alguns dos sites desses grupos são de 2010 e 2014. O GRAFAR, por exemplo, nem sequer possui um site, o que torna impossível saber se esta associação ainda existe.

Tais fatos podem dar a sensação uma área ainda fragilizada. Entretanto, através da formação de grupos é possível criar meios para a reflexão sobre a área através do oferecimento de workshops, seminários, eventos em geral em que se promove o diálogo entre os pares, sendo a troca um fator enriquecedor.

\section{A ILUSTRAÇÃO E A ACADEMIA}

Quando se busca o tema em artigos acadêmicos, pesquisas de mestrado e/ou doutorado em âmbito nacional são poucos os resultados encontrados, bem como quando se busca por congressos, livros etc. Um exemplo: se buscarmos por "ilustrador" no Portal de Periódicos da CAPES/MEC, serão exibidos apenas 52 resultados. Quando utilizado o termo em inglês "illustrator" aparecerão outros 6.041 resultados. Porém, se mudarmos a palavra de busca para "designer", por exemplo, serão exibidos 45.094 resultados. Já utilizando o termo "ilustração", encontraremos 511 resultados, "ilustración" outros 1.333 resultados e "illustration" outros 91.686 resultados. Entretanto, nada comparado a se utilizarmos "design", onde aparecerão 2.057.555 resultados. Isso demonstra que há pouca pesquisa, principalmente em português, para a área de ilustração.

Ou seja, além da falta de formação acadêmica para os "aspirantes a ilustrador", esse tema, de certa forma, é carente de atenção também dentro da comunidade acadêmica brasileira. Dentre esses pouquíssimos resultados apresentados é muito comum encontrarmos algo que tenha no nome a palavra "ilustração", porém quando analisado o conteúdo, mais aborda um artista específico, por exemplo, do que realmente o que é ilustração, se há um fundamento para o tema, que assuntos fazem parte desse universo etc.

Se existem poucos estudos específicos no Brasil sobre ilustração como área de conhecimento, então, como estão sendo preparados os professores para lecionar disciplinas que abordam o tema? Se há uma tendência a criarem cursos de graduação em design com um enfoque para a área, bem como disciplinas isoladas dentro da grade curricular de design, acredita-se que, por enquanto, os professores que

${ }^{7}$ O termo serve tanto para a língua portuguesa quanto para a língua espanhola. 
lecionam essas disciplinas possivelmente podem estar despreparados. Tal questão faz refletir sobre o que realmente está sendo oferecido como ilustração, se não há uma reflexão teórica sobre o assunto.

Em função dos problemas acima apontados que a SIB, a ACB, os GRAFAR e a ABRIPO se reuniram em 2007 a fim de redigir um documento de recomendação ${ }^{8}$ direcionado a instituições de ensino e professores de ilustração, para sugerir conteúdos que julgavam relevantes e indispensáveis aos futuros profissionais de comunicação (jornalismo, relações públicas, publicidade e propaganda, cinema, editoração e outras habilitações no campo da comunicação visual) que teriam a disciplina de ilustração na grade curricular do curso:

A conquista de uma cadeira universitária para a disciplina de ilustração é o reconhecimento acadêmico de um saber já posto na sociedade brasileira. [...] Em nossos dias, é inconcebível a linguagem de comunicação sem o acompanhamento visual, visto que a ilustração está maciçamente presente em todas as formas de comunicação: livros, revistas, jornais, TV, publicidade, cinema, vídeo game e internet. No futuro, colocado que a convergência midiática tende a ser característica dos novos tempos, tudo leva a crer que a ilustração terá papel de ainda maior relevância. (SIB et al.,2007)

Ou seja, temos uma demanda de parte de alunos inscritos em design, temos disciplinas relacionas ao tema, já começamos a lecioná-las de alguma forma ainda tímida, porém o que realmente está sendo oferecido enquanto conteúdo?

\section{CONCLUSÃO}

O texto aqui apresentado faz parte de uma análise para uma pesquisa de doutorado ainda em andamento, que objetiva identificar um elenco de temas e conteúdos pertinentes à formação de um ilustrador. De certa forma, é uma pesquisa que visa empreender uma reflexão sobre a formação de ilustradores e sobre a ilustração como uma área de formação específica.

Acredita-se que por mais que a oferta de uma nova graduação específica para ilustração seja algo muito complexo, pois demanda autorização do Ministério da Educação (MEC) e, principalmente, oferta e procura, não só de alunos, mas também de mercado de trabalho, é possível para as universidades criarem outras alternativas para esse público, como cursos livres, pós-graduação, habilitação em ilustração dentro de uma área já existente e, até mesmo, a criação de grupos de pesquisa sobre o tema.

A guisa de finalização fica uma pergunta: se grande parte desses ilustradores escolhem a graduação em Design $(41,3 \%)$, será que a mudança para uma formação mais adequada para esse tipo de público também não pode partir do design?

\section{REFERÊNCIAS}

ABIPRO. Documento de Análise para Regulamentação e Reconhecimento da Profissão de Ilustrador no Brasil (Dossiê Ilustração). Disponível em: <http://www.abri po.org/?scrid=Artigos.2006-04_Dossie_Flavio_Roberto_Mota_Grego>. Último acesso

\footnotetext{
${ }^{8} \mathrm{http}: / /$ www.tupixel.com.br/disciplina/recomendacao.pdf
} 
em: 03 jun 2016.

ANTUNES, Ricardo. Guia do ilustrador. Disponível em: http://www.guiadoilustrador. com.br/>. Último acesso em: 03 jun 2016.

SIB et al. Disciplina Ilustração nos cursos superiores de comunicação: uma recomendação. Disponível em: < http://www.tupixel.com.br/disciplina/recomendacao. pdf>. Último acesso em: 05 jun 2016.

\footnotetext{
i Lista de Grupos de discussão: 1. (Caderno pra Desenhos); 2. [DC] Desenhistas de Carros; 3. = llustração do Mundo = \{I.M $\}$; 4. A Arte Da Ilustração; 5. Amigos Desenhistas!; 6. Apaixonados por Desenhos; 7. Arte de Rabi\$car; 8. Arte HQs; 9. Arte Pública RJ; 10. Artes e Artesanato; 11. Artes e Artistas de Juiz de Fora; 12. Artes Visuais; 13. Bate-papo Ilustrado; 14. Bazar do desenhista; 15. Belas Artes - UFMG; 16. Belas Artes - UFRRJ; 17. Belas Artes de Lenita Crochês; 18. Caricaturistas; 19. Cartunistas \& Ilustradores da Baixada Santista SP; 20. Clube Belas Artes_Oficial; 21. Como Desenhar 9a Arte; 22. Concept Art \& Game Design; 23. Concept Art Brasil; 24. Concept Artists; 25. Concept Artist and Concept Art; 26. Cor na Estamparia; 27. Corel Painter Brasil Pintura Digital; 28. CRI4TIVO; 29. Crie Sua Arte; 30. Desenhista BR; 31. Desenhista/projetista - Autocad; 32. Desenhistas (grupo 1); 33. Desenhistas (grupo 2); 34. Desenhistas (grupo 3); 35. Desenhistas (grupo 4); 36. Desenhistas (grupo 5); 37. Desenhistas (grupo 6); 38. Desenhistas Amadores - Art; 39. Desenhistas BR; 40. Desenhistas de Araxá; 41. Desenhistas de Ubá; 42. Desenhistas do Facebook!; 43. Desenhistas do Mundo; 44. Desenhistas e Aprendiz; 45. Desenhistas FAB; 46. Desenhistas Piauienses; 47. Desenhistas Revolucionários; 48. Desenhistas Sem Fronteiras; 49. Desenhistas Top; 50. Desenhistas, Ilustradores e Artistas de Campos-RJ; 51. Desenho Artístico; 52. Desenho Artisticos vs Desenhos Tecnicos (Criativos disfarçados); 53. Desenho de moda; 54. Desenho e HQs; 55. Desenho logo existo!; 56. Desenhos e Photoshop; 57. Desenho é Vida!; 58. Desenho TUTO; 59. Desenhos (OFICIAL); 60. Desenhos 3D; 61. Desenhos a lápis; 62. Desenhos a mão livre; 63. Desenhos amadores a lápis; 64. Desenhos Animes; 65. Desenhos Arte; 66. Desenhos de um Mangaka; 67. Desenho e Técnicas de Ilustração 2014 - Senai; 68. Desenhos Iniciantes; 69. Desenhos Irados; 70. Desenhos para Vida/Drawing for life; 71. Desenhos Realista; 72. Desenhos Realistas; 73. Desenhos Seguros; 74. Design de Personagens; 75. Design Gráfico e Ilustração - AllSell Informática; 76. Designer Gráfico; 77. DeviantART Brasil; 78. deZENhistas; 79. Diretores de Arte Rio; 80. Divulgação e Ilustração de Ciência em Portugal; 81. DSG1535 - Desenho de Moda - 2016.1; 82. DSG1536 - Ilustração de Moda - 2016.1; 83. Duelo dos melhores desenhos; 84. EBA - UFRJ; 85. Ed/Ilustrador - Workshops e Oficinas de Ilustração; 86. Escola de Pintura Digital - Amadores e profissionais; 87. Esboços e Artes; 88. Eu Desenho; 89. Freela das minas: Ilustração e Texto; 90. Grupo de Ilustração de Dourados; 91. Grupo Edição de Imagem e Ilustração; 92. Grupo Ganbatte Desenhista; 93. Guilda de Desenhistas; 94. HQ's, Quadrinhos em Geral - Classificados de Troca e Venda; 95. IlustrAção; 96. Ilustração Botânica ESALQ; 97. Ilustração Científica - Workshop; 98. Ilustração Científica e Botânica; 99. Ilustração Científica na UA; 100. Ilustração de Aves - Grupo de Discussão; 101. Ilustração Depressão; 102. Ilustração Digital; 103. Ilustração Histórica - Historical Illustration; 103. Ilustração Infantil; 104. Ilustração/Animação UFSC; 105. Ilustradoras e Quadrinistas do Rio de Janeiro; 106. Ilustradores (grupo 1); 107. Ilustradores (grupo 2); 108. Ilustradores (grupo 3); 109. Ilustradores (grupo 4); 110. Ilustradores (grupo 5); 111. Ilustradores - Free Lance; 112. Ilustradores Brasil (grupo 1); 113. Ilustradores Brasil (grupo 2); 114. llustradores de BH; 115. Ilustradores de São Paulo; 116. Ilustradores em Ação; 117. Ilustradores Goianos; 118. Ilustradores Ilustres; 119. Ilustradores Infnéticos; 120. Ilustradores Naturalistas Latinoamericanos; 121. Ilustradores Recife; 122. Ilustradores Recife; 123. ilustradores SENAl; 124. Ilustradores Unidos; 125. Ilustragrupo; 126. Ilustres Ilustradores - Illustrious Illustrators; 127. Jovens Desenhistas; 128. Jovens Desenhistas SS; 129. Mostre Aqui seu Desenho Desenhista; 130. O Desenho é Minha Arte e Vida; 131. Pintura Digital (grupo 1); 132. Pintura Digital (grupo 2); 133. Pintura Digital - SENAI - Tijuca; 134. Polinhas; 135.Pratic4ndo; 136. PUC-Rio_Design; 137. Quadrinistas de Pernambuco; 138. Quadrinistas do Mato; 139. Quadrinistas e aspirantes ES; 140. Quadrinistas goiânos; 141. Quadrinistas, Desenhistas e o que mais quiserem...; 142. Redatores, Roteiristas, Diretores de Arte e Rabiscadores em geral; 143. Roteiristas, Ilustradores e Coloristas de HQ; 144. Setorial de Ilustração de Curitiba; 145. Sketchs \& Art - UVA; 146. Só Desenhos Realistas; 147. Só para Desenhistas; 148. TAGMAR - Ilustradores; 149. Tecnologia e Mídias Digitais (PUCSP); 150. Top Drawings - Minha Vitrine de Desenhos; 151. Turma de desenhistas; 152. UNIC - União Nacional de Ilustradores Científicos; 153. UVA - Ilustração e Pintura Digital (RCL) 2015.2; 154. Workshop de Pintura Digital - Black Fox Studio.
} 